\title{
Dual-Mode FEN1 Activity Detection Based on Nt.BstNBI-Induced Tandem Signal Amplification
}

Haitang Yang ${ }^{\mathrm{a}}$, Chenchen Wang ${ }^{\mathrm{a}}$, Ensheng $\mathrm{Xu}^{\mathrm{a}}$, Wei Wei ${ }^{\mathrm{a},{ }^{*}}$, Yong Liu $^{\mathrm{b}}$, Songqin $\mathrm{Liu}^{\mathrm{a}}$

${ }^{a}$ Jiangsu Engineering Laboratory of Smart Carbon-Rich Materials and Device, Jiangsu Province Hi-Tech Key Laboratory for Bio-medical Research, School of Chemistry and Chemical Engineering, Southeast University, Nanjing, 211189, China

${ }^{b}$ Henan Key Laboratory of Polyoxometalate Chemistry, College of Chemistry and Chemical Engineering, Henan University, Kaifeng, 475004, China 


\section{Table of contents}

\section{Chemicals and materials}

Figure S1 Fluorescence colors of CSG/ThT with different concentration of CSG DNA

Figure S2 Fluorescence colors of CSG/ThT with 0 and $2 \mu \mathrm{M}$ CSG DNA

Figure S3 Optimization of the experimental conditions.

Figure S4 Effects of ThT concentration for target FEN1 detection

Table S1 Sequences of oligonucleotides used in this study.

Table S2 Recovery experiments of FEN1 in human serum samples. 
Chemicals and materials. The oligonucleotides, deoxyribonucleotide triphosphates (dNTPs) and Bst DNA polymerase used in this paper were obtained from Shanghai Sangon Biological Engineering Technology \& Services Co. Ltd. (Shanghai, China). The DNA sequences used in this paper were listed in Table S1. Hemin and 3,3',5,5'-tetramethylbenzidine (TMB) were purchased from Aladdin Reagent Co., Ltd. (Shanghai, China). Thermostable FEN1 and Nt.BstNBI used in this study were purchased from New England Biolabs Inc. All other chemicals were of analytical reagent grade and used without any purification. Ultrapure water $(18.2 \mathrm{M} \Omega \mathrm{cm}$ at $25^{\circ} \mathrm{C}$, Barnstead, Thermo Scientific, USA) was used in all experiments.

In this study, the buffer solutions were employed as follows: Hybridization buffer (50 mM Tris-HCl, $50 \mathrm{mM} \mathrm{MgCl}$ ); 1×Thermo Pol Reaction Buffer (10 mM $\mathrm{KCl}, 20 \mathrm{mM}$ Tris- $\mathrm{HCl}, 10 \mathrm{mM}\left(\mathrm{NH}_{4}\right)_{2} \mathrm{SO}_{4}, 2 \mathrm{mM} \mathrm{MgSO}_{4}, 0.1 \%$ Triton X-100, pH 8.8); NEBuffer 3.1 (50 mM NaCl, $25 \mathrm{mM}$ Tris-HCl, $5 \mathrm{mM} \mathrm{MgCl} 2,50 \mu \mathrm{g} / \mathrm{mL} \mathrm{BSA}$, pH 7.9); Substrate buffer (containing $26.6 \mathrm{mM}$ citric acid, $51.4 \mathrm{mM} \mathrm{Na}_{2} \mathrm{HPO}_{4}$, and 50 $\mathrm{mM} \mathrm{KCl}, \mathrm{pH}=5.0)$ 


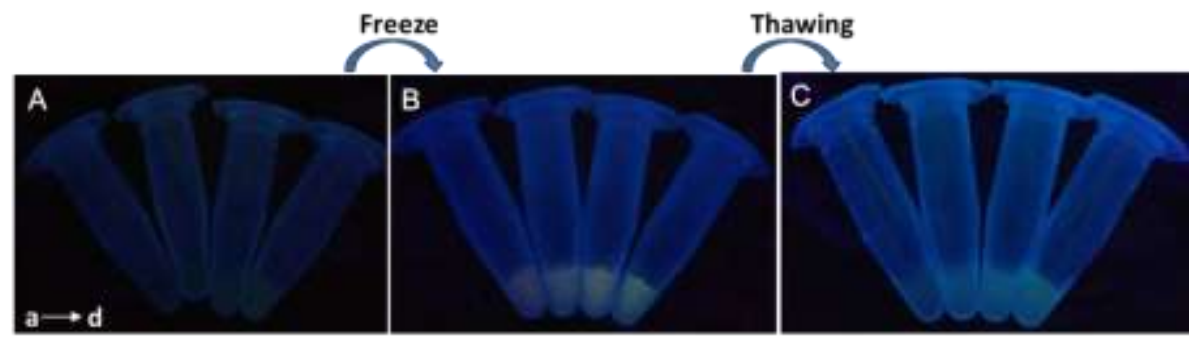

Figure S1 Fluorescence colors of ThT/CSG with different concentration (a:0 nM, b: $40 \mathrm{nM}, \mathrm{c}$ : $200 \mathrm{nM}$, d: $500 \mathrm{nM}$ ) at different state under a $365 \mathrm{~nm}$ UV lamp. 


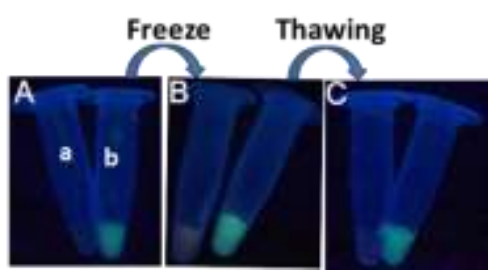

Figure S2 Fluorescence colors of CSG with a $(0 \mathrm{nM})$ and b $(2 \mu \mathrm{M})$ at different state under a 365 nm UV lamp. 

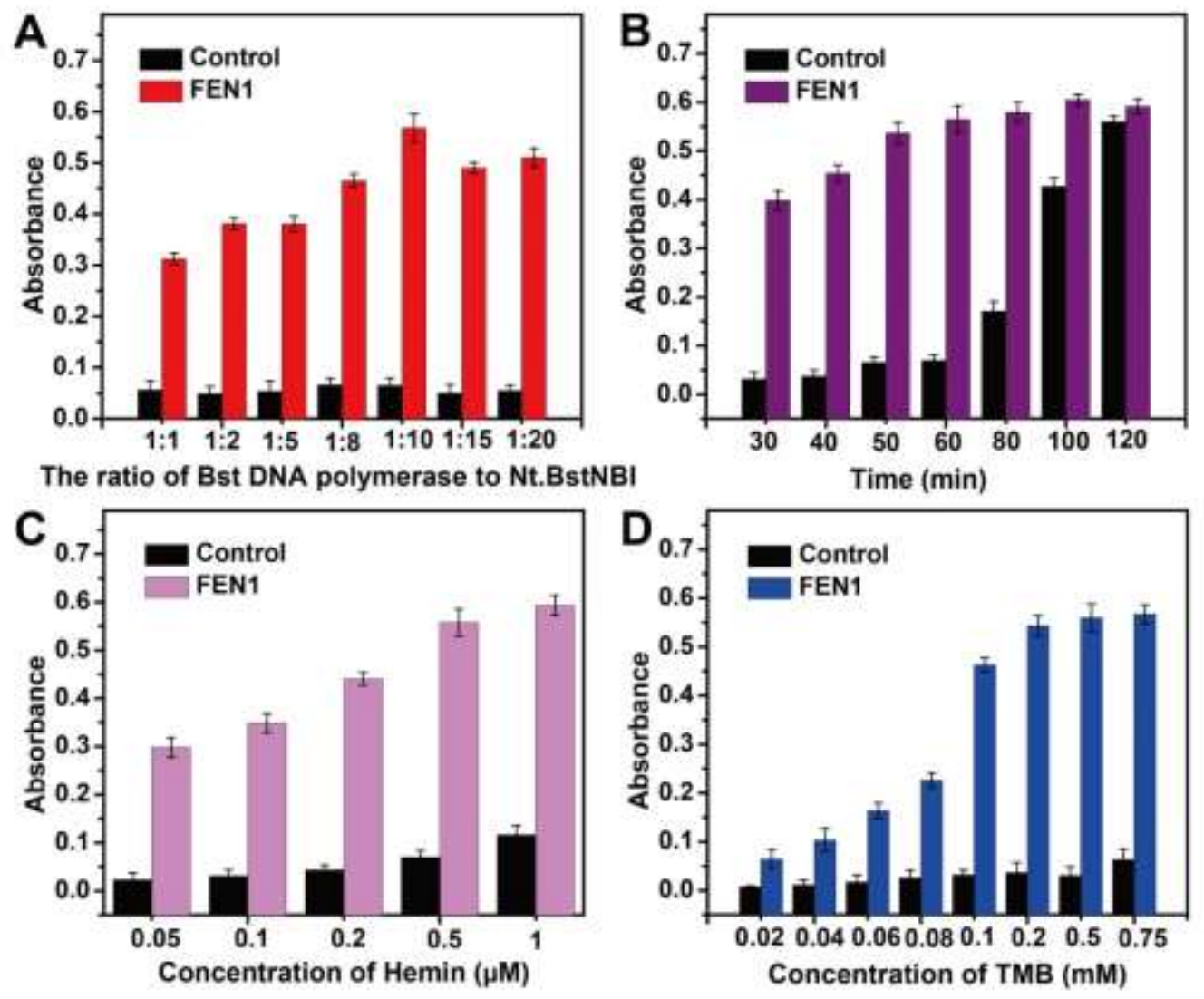

Figure S3 Optimization of the experimental conditions with 0.6 U FEN1. The effect of enzyme ratio of Bst polymerase to Nt.BstNBI (A), the reaction time for Bst polymerase and Nt.BstNBI (B), the concentrations of hemin (C) and TMB on the UV-vis response of the sensing system, respectively. In addition to the conditions to be optimized, other conditions remained the same. Error bars indicated the standard deviations of three experiments. 


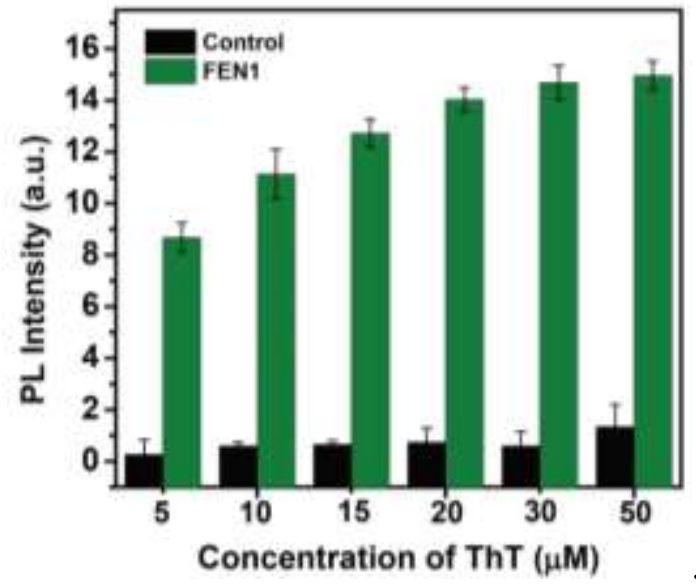

Figure S4 Effects of ThT concentration for target FEN1 detection. Error bars indicated the standard deviations of three experiments. 
Table S1. Sequences of the Oligonucleotides Used in the Experiments.

\begin{tabular}{cr}
\hline Name & Sequence (5' to 3') \\
\hline T1 & CCCCTCACGCTCCAATCACATCTAGTAACGTTCA \\
D & CCCCTCACGAGTGCCTGAGTGATTGGAGCGTGAGGGG \\
$\mathrm{U}$ & TGAACGTTACTAGATA \\
T2 & TAACCCTAACCCTAACCCTAACCCATCAACAGACTCACTCAGGCACTCGTGAGGGG \\
\hline
\end{tabular}


Table S2 Recovery experiments of FEN1 in human serum samples.

\begin{tabular}{llll}
\hline Added (U) & Found $(\mathrm{U})$ & Recovery $(\%)$ & RSD $(\%, \mathrm{n}=3)$ \\
\hline 0.1 & 0.09 & 90 & 5.1 \\
0.2 & 0.21 & 105 & 4.8 \\
0.4 & 0.38 & 95 & 3.6 \\
0.6 & 0.56 & 93.3 & 3.2 \\
\hline
\end{tabular}

